Conclusion There is need for more documentation of primary immunodeficiency disorders in order to empower clinicians to easily identify cases and offer prompt treatment.

\section{G595(P) REAL-LIFE CLINICAL EFFECTIVENESS OF CIDOFOVIR IN TREATING SYSTEMIC PAEDIATRIC ADENOVIRUS INFECTIONS}

C Devanahallinagaraj, S Kapoor, J Tang, A Price, J Bubb, S Bandi, M Joshi. University Hospitals of Leicester, Leicester, UK

10.1136/archdischild-2020-rcpch.512

Aim To report the clinical effectiveness of cidofovir in real-life paediatric patients with systemic adenovirus (AdV) infections and identify the AdV serotypes in these patients.

Method Retrospective data extracted from clinical records in a tertiary UK paediatric hospital.

Results Three children admitted to Paediatric Intensive Care Unit (PICU) with systemic AdV infection were identified between January 2017 and August 2019.

Case 1: 8-year old girl with a background of developmental delay secondary to birth-related HIE (hypoxic brain injury). She had normal immunoglobulins, lymphocyte subsets and vaccination responses excluding immunodeficiency. She presented with an acute lower respiratory tract infection (LRTI) and had AdV detected in her blood, nasopharyngeal aspirate (NPA) and urine. Her blood AdV viral loads were 1.22 million copies $/ \mathrm{ml}$ which dropped to 281 copies $/ \mathrm{ml}$ after 3 doses cidofovir over 11 days.

Case 2: 14-year old girl with a background of immunodeficiency and non -cystic fibrosis bronchiectasis, known to Immunology team presented with LRTI. At the time of the AdV (serotype 7) infection, she had a genetically undefined combined immunodeficiency. Her initial AdV loads were 16.4 million copies $/ \mathrm{ml}$ (blood) which dropped to 145 copies $/ \mathrm{ml}$ after 3 doses of cidofovir over 14 days.

Case 3: 23-month old healthy boy presented with respiratory symptoms but deteriorated rapidly and was transferred to PICU on high frequency ventilation, but eventually required ECMO support (extra-corporeal membrane oxygenation). Despite extensive immunological investigations, no specific immunodeficiency was identified. His NPA was positive for AdV (serotype 7) and his blood AdV level was 34 million copies/ml. His AdV blood levels dropped rapidly to 50 copies/ $\mathrm{ml}$ after 3 doses of cidofovir over the next 18 days along with intravenous immunoglobulin.

Conclusion AdV serotype 7 was identified in two of the three cases reported. Cidofovir treatment in our case series showed reduction in viral load and recovery. We noted no significant renal or hepatic impairment associated with cidofovir in any of the three cases. This case series highlights the use of cidofovir in paediatric population outside haemopoietic stem cell transplant and solid organ transplant recipients.

\section{G596(P) BRAIN ABSCESSES AND SOCIAL DEPRIVATION IN CHILDREN 2001-2018}

${ }^{1} \mathrm{~A}$ Faulkner, ${ }^{2} \mathrm{~A}$ Battersby, ${ }^{3} \mathrm{~F}$ van der Velden, ${ }^{4} \mathrm{M}$ Emonts, ${ }^{2,4} \mathrm{E}$ Lim. ${ }^{1}$ Medical School, Newcastle University, Newcastle upon Tyne, UK; ${ }^{2}$ General Paediatrics, Great North Children's Hospital, Newcastle upon Tyne, UK; ${ }^{3}$ Paediatrics, Franciscus Gasthuis and Vlietland Hospital, Rotterdam, The Netherlands; ${ }^{4}$ Paediatric Infectious Diseases and Immunology, Great North Children's Hospital, Newcastle upon Tyne, UK

10.1136/archdischild-2020-rcpch.513
Background The area of the UK studied has a higher incidence of paediatric brain abscess (BA) than the national average (8.92 per million) but it is unclear why. $24 \%$ of all children in this area live in poverty rising to $30 \%$ in the city itself above the national average of $20 \%$. We hypothesized that the increased incidence of brain abscesses was associated with social deprivation. Associations between deprivation and meningococcal disease and bacterial infections have been found both in the UK, Europe and the US.

Aims To examine the sociodemographic characteristics and identify any associations between socialdeprivation and incidence of paediatric brain abscesses.

Methods This was a retrospective cohort study. Data was examined from 115 confirmed cases of brain abscesses in children and young people aged 0-16 years admitted to our tertiary hospital between 01/01/2001 and 31/12/2018. All children from the region were referred to this tertiary neurosurgical service. Patient information was collected from patient notes or from an established database.

Patients' postcodes were linked to data from The English Indices of Deprivation 2015, which is the official measure of relative deprivation for small areas in England. This included the index of multiple deprivation, Income Deprivation Affecting Children, employment, education, health crime, barriers to housing and services and living environment deprivation. Data for brain abscess incidence and patient outcomes was plotted against deprivation indices.

Results Brain abscesses were over thirty times more common in the most deprived centile compared to the least. BA frequency was found to have a positive relationship with 'Health' and 'Income' deprivation.

Conclusions Our findings suggest that the incidence of brain abscesses may be associated with social deprivation in children and young people. More research is required to establish which parameters of social deprivation are most significant and to confirm this in subsequent studies

\section{G597(P) ABSTRACT WITHDRAWN}

\section{G598(P) ABSTRACT WITHDRAWN}

\section{G599(P) DESIGN AND IMPLEMENTATION OF A DATABASE FOR REAL-TIME REPORTING AND ANALYTICS OF PAEDIATRIC ALLERGY OUTPATIENT CLINIC ATTENDANCES AND OUTCOMES IN THE NORTH WEST OF ENGLAND AND NORTH WALES}

${ }^{1} \mathrm{D}$ Denaxa, ${ }^{1} \mathrm{~A}$ Ghattamaneni, ${ }^{2} \mathrm{~S}$ Dixon, ${ }^{2} \mathrm{~L}$ Niland, ${ }^{3} \mathrm{P}$ Arkwright, ${ }^{3} \mathrm{C}$ Lumsden. ${ }^{1}$ Paediatric Allergy and Immunology, Royal Manchester Children's Hospital, Manchester, UK; ${ }^{2} N W A P N$, Royal Manchester Children's Hospital, Manchester, UK; ${ }^{3}$ NWAPN and Manchester University, Royal Manchester Children's Hospital, Manchester, UK

\subsection{6/archdischild-2020-rcpch.514}

Aim Outpatient workload for paediatric specialities across a region, let alone within a specific centre is usually difficult to gauge. We aimed to develop an online database for recording and assessing workload in real-time. 